\title{
Fifty years of data show the effects of climate on overall skull size and the extent of seasonal reversible skull size changes in the common shrew
}

\author{
Jan Taylor ${ }^{1}$, Marion Muturi², Javier Lázaro ${ }^{2}$, Karol Zub $^{3}$, and Dina Dechmann ${ }^{2}$ \\ ${ }^{1}$ University of Bialystok \\ ${ }^{2}$ Max Planck Institute of Animal Behavior \\ ${ }^{3}$ Mammal Research Institute Polish Academy of Sciences
}

January 26, 2022

\begin{abstract}
1. Global climate change affects many aspects of biology and has been shown to cause body size changes in animals. However, suitable datasets allowing the analysis of long-term relationships between body size and climate are rare. 2. The size of the skull, often used as a proxy for body size, does not change much in fully grown vertebrates, but some soricine shrews shrink their skull and brain in winter and regrow it in spring. This is thought to be a winter adaptation in these high-metabolic, nonhibernating animals, as a smaller brain size reduces energy requirements. 3. Climate could thus affect not only the overall size but also the pattern of the size change, i.e., Dehnel's Phenomenon, in these shrews. 4. We assessed the impact of the changes in climate on the overall skull size and the different stages of Dehnel's phenomenon in skulls of the common shrew, Sorex araneus, collected over 50 years in the Białowieża Forest, NE Poland. 5. Overall skull size decreased, along with increasingly mild winters and decreasing soil moisture, which determined the availability of the shrews' main food source, earthworms. The magnitude of Dehnel's phenomenon increased over time, indicating an increasing selection pressure on animals in winter. Overall, climate clearly affected the common shrew's overall size as well as its seasonal size changes. With the current acceleration in climate change, the effects on the distribution range of this cold-adapted species may be quite severe.
\end{abstract}

Fifty years of data show the effects of climate on overall skull size and the extent of seasonal reversible skull size changes in the common shrew

Jan R.E. Taylor ${ }^{1}$, Marion Muturi ${ }^{2,3}$, Javier Lázaro ${ }^{2,3}$, Karol Zub ${ }^{4}$, Dina K.N. Dechmann²,3

${ }^{1}$ Faculty of Biology, University of Białystok, 15-245 Białystok, Poland

${ }^{2}$ Department of Migration, Max Planck Institute of Animal Behavior, 78315 Radolfzell, Germany

${ }^{3}$ Department of Biology, University of Konstanz, 78457 Konstanz, Germany

${ }^{4}$ Mammal Research Institute, Polish Academy of Sciences, 17-230 Białowieża, Poland

Correspondence

Jan R.E. Taylor, Faculty of Biology, University of Białystok, ul. Ciołkowskiego 1J, 15-245 Białystok, Poland. E-mail:taylor@uwb.edu.pl

\section{Abstract}


1. Global climate change affects many aspects of biology and has been shown to cause body size changes in animals. However, suitable datasets allowing the analysis of long-term relationships between body size and climate are rare.

2. The size of the skull, often used as a proxy for body size, does not change much in fully grown vertebrates, but some soricine shrews shrink their skull and brain in winter and regrow it in spring. This is thought to be a winter adaptation in these high-metabolic, nonhibernating animals, as a smaller brain size reduces energy requirements.

3. Climate could thus affect not only the overall size but also the pattern of the size change, i.e., Dehnel's Phenomenon, in these shrews.

4. We assessed the impact of the changes in climate on the overall skull size and the different stages of Dehnel's phenomenon in skulls of the common shrew, Sorex araneus, collected over 50 years in the Białowieża Forest, NE Poland.

5. Overall skull size decreased, along with increasing temperatures and decreasing soil moisture, which determined the availability of the shrews' main food source, earthworms. The magnitude of Dehnel's phenomenon increased over time, indicating an increasing selection pressure on animals in winter. Overall, climate clearly affected the common shrew's overall size as well as its seasonal size changes. With the current acceleration in climate change, the effects on the distribution range of this coldadapted species may be quite severe.

Key words: body size, skull size, climate change, Dehnel's phenomenon, shrews

Dear Editor,

Please consider our manuscript entitled "Fifty years of data show that climate affects overall skull size, and the extent of seasonal reversible skull change in the common shrew" for publication in your journal.

In today's changing world we are all becoming aware of the severe impact climate change has and will continue to have on biodiversity. However, we lack studies that cover large enough time periods to really address this question. Here we present an analysis of a dataset that, we think, is unique for two main reasons: a) it adresses a 52-year time range, including the onset of climate change and b) the animal model is a species that is likely very sensitive to global warming as it has a predominantly Northern distribution. In addition, our model, the common shrew has an extremely high metabolism and does not hibernate, making winter a sensitive season for them. As an adaptation to this, the shrews shrink in winter and regrow in spring. Only a collection such as the one from the Mammal Research Institute in Poland that we used, which contains animals collected year-round, allows to address climate change related questions in this species.

Body size (as measured by the skull) is a well-established measure in this species and it shows patterns opposite to what you would expect with larger within-species body sizes towards the South. We present a thorough analysis incorporating a large number of environmental variables showing that this species is indeed affected by climate change and, along with the many other species in the genus Sorex, will likely continue to do so.

We thus believe that this paper does not only document the effect of climate change in a particularly extensive dataset, but also sends an urgent message and will be widely received by a broad audience.

Yours faithfully,

Jan R.E. Taylor and co-authors

\section{Introduction}

Global climate change affects animals in many ways, from phenology, geographic distribution, and phenotypic traits to distributions and population dynamics (Walther et al. 2002; Parmesan 2006; Gardner et al. 2011). Changes in phenotypic traits correlated with global warming mainly involve temporal trends in body mass and size (Gardner et al. 2011), two traits that are pivotal for individual life histories (Sauer and Slade 1987). Importantly, although mass and size are often used interchangeably, their change arises from different 
underlying physiological mechanisms. Mass is more sensitive to short-term environmental conditions affecting fat stores and the mass of the gastrointestinal tract and other organs (Piersma et al. 1999; Hume et al. 2002; Canale et al. 2016).

How climate influences body size is often described based on Bergmann's rule, which in its commonly used version describes a positive relationship between body size and latitude within species. Individuals of many homeothermic species are smaller at lower latitudes where temperatures are higher (e.g., Ashton et al. 2000; Ashton 2002). This implies that a similar relationship should occur in response to temperature change over time. It has been postulated that a decrease in body size is the third universal response to contemporary global warming in addition to changes in distribution and phenology (Gardner et al. 2011). Although the majority of studies did not find significant temporal changes in the sizes of birds and mammals, there are many examples of long-term body size and body mass changes (recorded over one to several decades) correlated with global climate change. While a decrease in size is indeed the major response in birds, the situation is much less clear in mammals, where many species increase in size (Teplitsky and Millien 2014; Naya et al. 2017; Nengovhela et al. 2020). This increase in size is usually explained as a reaction to increased food availability as a result of increasing temperatures (Yom-Tov and Geffen 2011; Boutin and Lane 2014 and references cited therein).

Soricine (red-toothed) shrews, especially Sorex shrews, are an excellent study system to investigate climate change-induced patterns in species-level body size changes. They have extremely high metabolic rates, much higher than expected for their body mass (Taylor 1998; Ochocińska and Taylor 2005). Consequently, shrews require a constant high food supply (Hanski 1994; Keicher et al. 2017). In addition, the body size of several Sorex species, represented by skull length, shows positive correlations with temperature and negative correlations with latitude across their distribution range, contrary to Bergmann's rule (Ochocińska and Taylor 2003). It was suggested that food scarcity during winter in cold northern climates is a major factor selecting for small body size in shrews. This is in line with the "Resource Rule" of McNab (2010), which posits that "mammalian species will become larger or smaller depending on the size, abundance and availability of resources". A decrease in body size with latitude and in cold areas was also found in the masked shrew, Sorex cinereus, in Alaska and was also interpreted as related to better food resources in warmer areas (Yom-Tov and Yom-Tov 2005). In agreement with this, the body size of $S$. cinereus in Alaska increased during the second half of the twentieth century along with increasing temperature, presumably due to increasing food availability in winter (Yom-Tov and Yom-Tov 2005). However, an increasing temperature, especially when coupled with a decrease in precipitation, can also lead to a decrease in food resources. Drought has a negative impact on the abundance of the shrews' invertebrate prey (Coyle et al. 2017). This includes earthworms (Lumbricidae), the main food of the common shrew, S.araneus (Shchipanov et al. 2019), the availability of which depends on high soil moisture (Coyle et al. 2017; Singh et al. 2019).

The importance of small size in soricine shrews under unfavourable conditions (caused directly or indirectly by climate) is also visible in the remarkable seasonal morphological changes they exhibit. Individual skeletal size in endotherms remains more or less inert once full size is reached, which occurs rapidly in small mammals, and climate change causes size changes in the skeleton at the species or population level. However, soricine shrews undergo a profound seasonal and reversible transformation: individual seasonal shrinkage and regrowth of the skull and brain along with other organs and tissues (Dechmann et al. 2017; Lázaro et al. 2017). This change in the skull shape and height as well as the body mass of soricine shrews and some other small highmetabolic animals is called Dehnel's phenomenon (Dehnel 1949; Pucek 1963, 1970; Dechmann et al. 2017). After juveniles are fully grown, their brain mass decreases by $21 \%$ on average, and skull height decreases by $13 \%$ in $S$. araneus. Their brain mass reaches a minimum value in winter and then partially regrows in spring (Lázaro et al. 2021). Body mass, in contrast, decreases in anticipation of winter and then almost doubles in spring as the animals achieve sexual maturity. $S$. araneus, born in early summer, has a maximum lifespan of approximately 14 months, and almost all individuals die before the second winter (Pucek 1981). The size decrease in winter is thought to be an adaptation to harsh climatic conditions in these nonhibernating, high-metabolic animals. The low body mass in shrews in winter has been hypothesized to reduce absolute food requirements when food availability is limited (Mezhzherin 1964; McNab 1991; Taylor et al. 2013). 
Accordingly, small winter animals have the same mass-corrected energy consumption as larger, first and second summer shrews, even under ambient conditions with temperatures differing by as much as $30{ }^{\circ} \mathrm{C}$ (Schaeffer et al. 2020). This results in absolute energy savings in winter and correlates with reduced food requirements. Disproportionally reducing the size of the brain, an energetically expensive tissue (Aiello and Wheeler 1995; Isler and Schaik 2006), may lead to further energy savings.

The magnitude of the decline in skull height in $S$. araneus , a commonly used proxy for Dehnel's phenomenon, increases towards the northeast and is linked to large-scale environmental conditions and probably also the local habitat structure (Pucek 1970; Lázaro et al. 2021). It is positively correlated with temperature seasonality, annual temperature range, and other climate parameters, although no such relationships have been observed with the skull height regrowth (Lázaro et al. 2021), which has led to the hypothesis that the shrinking may be the result of different evolutionary drivers than the regrowth. In line with these observations, the individual decrease in skull height in $S$. araneus is flexible and modulated by ambient temperature (Lázaro et al. 2019).

Our aim was to confirm that the change in climate over several decades has had an impact on 1) the overall size of $S$. araneus as measured by skull dimensions and 2) the intensity of the reversible seasonal size change (Dehnel's phenomenon). We combined climate data and skull size measurements of $S$. araneus from a 52-year series of specimens collected in the Białowieża primeval forest, NE Poland, from 1953 to 2004.

We first hypothesized that, because they are larger at lower, warmer latitudes, the body size of $S$. araneus increased over the years as a response to increasing temperatures or decreased as a response to a dryer climate leading to a decreasing soil water level and thus lower earthworm availability in the Białowieża Forest. We further hypothesized that there should be a negative relationship between the winter skull height decrease and winter temperatures. Conversely, the winter skull height decrease should become greater if climate change is combined with increasingly less favourable food availability in winter than in summer.

\section{Methods}

\subsection{Shrews, study area and trapping}

Sorex araneus (Figure 1) were collected between 1953 and 2004 in Białowieża National Park, preserved in alcohol and stored in the zoological collection of the Mammal Research Institute, Polish Academy of Sciences, in Białowieża. Shrews were trapped in a mesic broadleaved forest with a transition to a moist broadleaved forest, mainly in compartment No. $371\left(52^{\circ} 44^{\prime} \mathrm{N}, 23^{\circ} 52^{\prime} \mathrm{E}\right)$ but also in adjacent Nos. 369 and 370 (see Dehnel 1949 for a map; all these compartments are in the strict reserve). This type of forest is classified as a subcontinental oak-lime-hornbeam forest Tilio-Carpinetum. The mean age of the trees exceeded 100 years, and the amount of dead wood on the ground averaged $50 \mathrm{~m}^{3} \mathrm{ha}^{-1}$.

S. araneus were caught with pitfall traps (cylinders $30 \mathrm{~cm}$ deep and cones $45 \mathrm{~cm}$ deep). After 1965, wooden live traps were additionally used. We selected and measured the skulls of shrews from the three main stages of Dehnel's phenomenon: summer individuals in their first calendar year (hereafter "juveniles") caught from July to August, winter individuals ("subadults") caught from December to February, and mature spring/summer individuals in their second calendar year ("adults") caught from April to August. After 1981, juvenile individuals were trapped only in July. There was no winter trapping at all after 1985 . We also measured three individuals each from June (juveniles), September (juveniles) and November (subadults) from 1955-1985. The sex of all individuals (determined by dissection) was noted on their labels.

\subsection{Measurements of skull dimensions}

A single observer measured the skull height, length and width (MM) using X-ray images of the alcohol preserved specimens, as described by Lázaro et al. (2017). Briefly, skull length was measured from the anterior-most projection of the first incisive tooth to the occipital condyle (Figure 2a); skull height was measured from the dorsal outline of the braincase to the orthogonal line defined by the ventral outlines of the pterygoid process and occipital condyle, passing over a constant proportional distance on the line defined by the skull length (Figure 2a); skull width was the greatest lateral diameter of the braincase (Figure 2b). The 
technical error of measurement (standard deviation of the repeated measurements of the same individual as the $\%$ of the mean) for the skull length, height and width was $1.35 \%, 2.04 \%$, and $1.89 \%$, respectively (supplemental information in Lázaro et al. 2017). We measured a total of 503 skulls.

\subsection{The choice of months representing the three age categories}

We compared skulls in three age categories of individuals that characterize their entire lifetime: fully grown juveniles, size-decreased subadults, and regrown adults (Figure 3). To test the homogeneity of each age category, we used an ANCOVA model with the month as a factor, the time (year) as a covariate, and the interaction between month and year. The skull height of juvenile individuals differed between July and August $\left(F_{1,201}=8.08, P=0.0049\right)$, and the interaction was significant $\left(F_{1,201}=8.12, P=0.0048\right)$ in the period between 1953 and 1981, when individuals from both months were measured. Thus, we further analysed July and August juveniles separately.

The interaction between month and year was not significant in the analogous ANCOVA model for skull height in subadults from December, January, and February $\left(F_{2,82}=0.75, P=0.476\right)$. However, skull height had not fully decreased in December and was higher than in January and February when we removed the interaction from the model $(P=0.0159$ and $P=0.0426$, respectively). The skull height did not differ in the model that included only the month and year for skull height in subadult shrews from January and February $\left(F_{1,67}=0.55, P=0.461\right)$, and we used only these months for further comparisons (Figure 3). In these two months, the skull height was lowest in the lifespan of $S$. araneus (Dehnel 1949; Pucek 1970). Moreover, the lack of an interaction between month and year in December, January, and February indicated that skull height reached a minimum in January irrespective of the year. In adults (Figure 3), neither the year $\times$ month interaction nor the month was significant in the model for skull height $\left(F_{4,104}=0.88, P=0.476 ; F_{4,104}=0.88\right.$, $P=0.477)$. The month was also nonsignificant $\left(F_{4,108}=1.67, P=0.163\right)$ when the interaction was removed from the model. Thus, we retained all months from April to August in the final analyses of adults.

We ran the same tests for skull width and length, which varied much less between seasons (Lázaro et al. 2017). The year $\times$ month interaction was not significant in any age category, and there were no significant differences between collection months. See Figure 4 for an overview of analysed $S$. araneus data.

\subsection{The change of skull size from 1953 to 2004}

We first analysed the changes in the overall size of $S$. araneususing the full dataset from 1953-2004, which was only available for juveniles in July and adults. We tested the significance of the slopes of the linear regressions of all three dimensions over time: skull height, width, and length. We added a quadratic term to the linear model to test for linearity of the relationships and determine whether it improved the model according to an F test with a type I sum of squares. However, inspection of the residuals from the linear regression suggested a more subtle nonlinearity of the skull size over time. Thus, we additionally used locally weighed regression smoothing (LOESS; Cleveland 1979). We selected the smoothing parameter by minimizing Akaike's information criterion, which strikes a balance between the residual sum of squares and the complexity of the fit.

\subsection{The influence of climate change on size of $S$. araneus}

We examined the weather data from Białowieża from 1952-2004 to explain changes in skull size in juvenile and adult $S$. araneus. We obtained the mean daily temperature $\left({ }^{\circ} \mathrm{C}\right)$, rainfall $(\mathrm{mm})$ and snow cover $(\mathrm{mm})$ from the Białowieża Meteorological Station. We summed or averaged these daily measures for longer periods and computed the soil moisture deficit from monthly temperatures and precipitation using the Watbug program (Willmott 1977). Monthly deficits were summed for years or other periods as indicated below. As in the previous section, we used linear regression, tested for nonlinearity by adding quadratic terms, and smoothed the relationships with LOESS.

We averaged each of three skull measurements over each year and regressed averages against weather variables after weighting by sample size. We calculated the mean daily temperature, sum of the precipitation, and sum of the moisture deficit in the soil in the period preceding the collection of specimens (from their approximate 
time of birth; see Results for details). We checked for a temporal autocorrelation (correlation of residuals in neighbouring years) in juvenile shrews using the Durbin-Watson statistic. To account for the effect of significant autocorrelation, we corrected the regressions with the Cochrane-Orcutt procedure. We corrected all regressions using adult shrews because the smaller sample size (32 years) did not allow us to test for autocorrelation. The results are shown as the coefficients $r^{2}$, the proportion of the skull size variation explained by weather variables.

\subsection{Skull dimensions in all three age categories from 1955 to 1985}

We compared absolute values of the skull height, width, and length for the years when specimens for all three age categories were available in an ANCOVA with age as the factor and sampling year as the covariate.

\subsection{Change in the magnitude of Dehnel's phenomenon from 1955 to 1985}

We compared the amount of change in the skull height, length, and width from the data subset where we had data from all three size extremes (summer juveniles, winter subadults, regrown adults). Additionally, we tested for the effect of time on seasonal changes in relative skull size (skull height and skull width corrected for skull length). To do this, we compared juveniles (July and August separately) with subadults and subadults with adults in ANCOVA models with age as the factor, year and skull length as the covariates, and the interaction between year and age.

To visualize the change in the magnitude of Dehnel's phenomenon over time, we divided the years where we had data from all three size extremes (summer juveniles, winter subadults, regrown adults) into three time intervals (1953-1963, 1964-1974, 1975-1985). We compared the seasonal curves of the skull height between these time intervals with a generalized additive model (GAM) using the "time interval" as a parametric term and "month" as a nonparametric term. We used a Gaussian distribution and added a smoothing function to "month" with knots restricted to five (because we had an a priori expectation for the presence of the shape of a seasonal skull height pattern).

\subsection{Statistics}

We used general linear models (GLMs) for ANOVA and ANCOVA models. Multiple comparisons between means after the ANOVA were performed with Tukey-Kramer tests. We tested the significance of all possible interactions between covariates and factors in all ANCOVA models and reported all significant results. The above tests and LOESS smoothing were performed in SAS ver. 9.4 (SAS Institute, Cary, NC, USA). GAM models were fitted with R (ver. 3.3.1; R Core Team 2016).

\section{Results}

\subsection{The change of skull size from 1953 to 2004}

The skull height and width, but not the length, were larger in adult males than in females in $S$. araneus, as confirmed in the ANCOVA models with sex and year $\left(F_{1,110}=7.20, P=0.0084 ; F_{1,110}=11.25, P=0.0011 ; F\right.$ $1,110=1.00, P=0.320$; the interaction between the sex and year added to the models was nonsignificant: $F$ $\left.{ }_{1,109}=0.14, P=0.711 ; F_{1,109}=0.36, P=0.552 ; F_{1,109}=0.37, P=0.543\right)$. Nonetheless, as we were mainly interested in relative change and because otherwise sample sizes would have been too small, we pooled the sexes for further analyses.

The skull height and width of juvenile and adult $S$. araneus, as well as the skull length of juveniles, decreased significantly over the sampling period. In contrast, the relationship between skull length and time was not significant in adults (linear regression models; Table 1; regression equations are in supporting information, Table S1). Characteristically, all these relationships (except skull height in adults) revealed a common pattern when smoothed with LOESS: little change until the early 1970s and decreases thereafter (Figure 4; scatterplots in supporting information, Figure S1). The decrease in skull width of adults from 1970 to 2004 was even sharper than that in the entire time period $\left(F_{1,70}=11.46, P=0.0012\right)$. The decrease in the skull length of adults was significant when restricted to this time period $\left(F_{1,70}=8.79, \mathrm{P}=0.0041_{\text {and }} F_{1,69}=4.99\right.$, $\mathrm{P}=0.0288$ when one outlier in 2004 was removed). 


\subsection{The influence of climate change on the size of $S$. araneus}

The weather records from this period revealed several significant trends indicative of a changing climate (scatterplots of six climate parameters are shown in Figure S2). The mean annual temperature increased significantly $\left(F_{1,51}=28.1, P<0.0001\right.$; Figures $4 \mathrm{c}$ and S2a) from $6.1{ }^{\circ} \mathrm{C}$ to $8.2{ }^{\circ} \mathrm{C}$ (as calculated from the regression line). There was also an increase in the mean July temperature $\left(F_{1,51}=10.5, P=0.0021\right.$; Figure $\mathrm{S} 2 \mathrm{~b})$, from $17.2^{\circ} \mathrm{C}$ to $19.7^{\circ} \mathrm{C}$, but not in the mean January temperature $\left(F_{1,51}=2.29, P=0.136\right.$; Figure S2c). The relationship of the sum of annual precipitation with time was nonlinear (quadratic term: $F_{1,50}=9.30$, $\mathrm{P}=0.0037$ ), with an initial increase leading to a maximum in the mid-1970s, followed by a decrease until 2004 (the decrease in 1971-2004 was statistically significant: $F \quad 1,32=11.25, P=0.0021$, linear regression) (Figures $4 \mathrm{~d}$ and S2d). The period of high precipitation was mainly due to increased rainfall in June and July. Continuous increases in mean annual and mean July temperatures coupled with a significant decline in precipitation resulted in an increased nonlinear soil moisture deficit over the years (quadratic term: $F$ $1,50=7.69, P=0.0078 ;$ Figures $4 \mathrm{e}$ and $\mathrm{S} 2 \mathrm{e})$. This change in the deficit was not significant until $1971(F$ $1,18=0.20, P=0.660$, linear regression), but there was a significant increase in the soil moisture deficit after 1971 ( $\left.F_{1,32}=11.9, P=0.0016\right)$. Interestingly, the beginning of the increase in drought corresponded with the inflection points of the smoothed relationships of the skull size vs. years and with the clear decrease in skull size later on (Figure 4). The number of days with snow cover significantly decreased over the study period $\left(F_{1,51}=4.57, P=0.0374\right)$ (Figure $\left.\mathrm{S} 2 \mathrm{f}\right)$.

We found no significant relationships between skull length and the climate parameters in either juvenile or adult shrews in the whole time series, i.e., between 1953 and 2004. However, when we reduced this period to between 1971 and 2004 (the time of the significant decrease in skull length in adults), the relationship between the skull length and the moisture deficit in the soil became highly significant $\left(F_{1,20}=6.91, P=0.0161, r^{2}\right.$ $=0.257$ ); an increased deficit resulted in a shorter skull length (Figure 5).

The analysis of the relationships between skull height and climate between 1953 and 2004 revealed significant temperature effects (Table 2). Skull height decreased significantly with increasing mean daily temperatures during the expected lifetime in both juvenile and adult shrews. We also found an impact of winter weather (during the subadult stage) on adult skull height the following summer: the increase in the lowest average daily temperature in February (but not in January) was associated with the decrease in skull height in summer, but this relationship was marginally significant. Moreover, summer skull heights were greater when there were more days with snow cover in the previous January and February. However, the relationship between skull height and the number of days with snow cover $>=5 \mathrm{~cm}$ in January and February did not reach the significance level (Table 2). Following this pattern in other analyses, there were no significant relationships between skull width and climate parameters. Including more than one weather variable in a model never increased the overall significance.

\subsection{Skull dimensions in all three age categories from 1955 to 1985}

Skull height, width, and length were significantly correlated with age (confirming the typical seasonal size change pattern; Table 3A). Only the skull height showed a negative significant relationship with year, and the interaction between year and age was significant when included in this model $\left(F_{2,289}=5.23, P=0.0058\right)$.

All measures of skull size differed significantly between the age categories (Table 3B). Skull height decreased significantly by $14.4 \%$ from summer juveniles to winter subadults and regrew by $7.4 \%$ in the following summer adults. Skull width followed this pattern with a lesser but statistically significant decrease of $1.4 \%$ and then an increase of $1.9 \%$. The $2.0 \%$ decrease in skull length from juveniles to subadults was also statistically significant (Table $3 \mathrm{~B}$ ).

\subsection{Change in the magnitude of Dehnel's phenomenon from 1955 to 1985}

The magnitude of Dehnel's phenomenon increased over the tested time period (Figure 6a). The skull height of August juvenile and subadult shrews decreased significantly over time $\left(F_{1,50}=11.83, P=0.0012 ; F\right.$ $1,68=19.52, P<0.0001$, respectively $)$ but did not change in July juvenile and adult shrews $\left(F_{1,149}=1.34\right.$, 
$P=0.249 ; F_{1,72}=0.00, P=0.985$; Figure $6 \mathrm{~b}$ ). This is also illustrated in Figure 6a: the standard errors of juvenile and adult skull height overlapped considerably, while the subadult skull height decreased strongly over time (years). There was no significant change in the skull length of August juveniles, subadults or adults $\left(F_{1,50}=0.00, P=0.978 ; F_{1,68}=0.05, P=0.829 ; F_{1,72}=0.07, P=0.942\right.$, respectively), but the change was significant in July juveniles $\left(F_{1,149}=5.00, P=0.0269\right)$.

In a second approach to analyse the magnitude of Dehnel's phenomenon, we compared the slopes of the regression lines of skull height over time (years) between juveniles vs. subadults and subadults vs. adults (Figure 6b, scatterplots in Figure S3, see also Figure 4a). A lack of interaction between the year and age (parallel lines) would indicate no change in Dehnel's phenomenon. We explored this in an ANCOVA model of the skull height with the skull length, year, age, and year $\times$ age interaction (Table 4). Year and skull length were highly significant in the comparison of July juveniles with subadults, August juveniles with subadults, and subadults with adults (Table 4). The interaction between year and age was highly significant in two comparisons (Table 4): the decline in skull height from July juveniles to subadults was greater with time (Figures 6b and S3a), and the regrowth in skull height from subadults to adults increased over time (Figures $6 \mathrm{~b}$ and S3c). In both cases, this was due to the very steep line in subadults. In contrast, the interaction was nonsignificant in the comparison of August juveniles with subadults (Table 4, Figures 6b and S3b). The lines of July and August differed significantly in slope (the interaction between month and year: $F$ 1,198 $=12.60$, $\mathrm{P}=0.0005$ in ANCOVA with year: $F_{1,198}=14.72, \mathrm{P}=0.0002$; month: $F_{1,198}=12.55, \mathrm{P}=0.0005$; skull length: $F$ $1,198=27.57, \mathrm{P}<0.0001$; Figure $6 \mathrm{~b}$ ). The skull width of juveniles (July, August) and adults did not change significantly over time (Table S2). The year $\times$ age interaction was not statistically significant in any of the three models for length-corrected skull width (Table S3). When these interactions were removed from the models, age was significant only in the comparison of subadults and adults, and the year was never significant (Table S3).

To discuss the impact of weather on Dehnel's phenomenon, we additionally tested the regressions of all weather parameters on time (years) in July, August and January between 1955 and 1985. The only significant regression was that of the August mean daily temperature (positive relationship; $F_{1,29}=6.36, P=0.0175$ ). However, the mean daily temperature in January decreased significantly during the first $60 \%$ of the tested period ( 1955 to $1972 ; F_{1,16}=8.16, P=0.0114$, and $F_{1,15}=19.9, P=0.0005$ when one clear outlier was removed; Figure S2c).

\section{Discussion}

\subsection{Decrease in skull and thus overall size over time (1953-2004)}

Skull dimensions of juvenile and adult $S$. araneus significantly decreased during the study period (Table 1). Skull length, the often-used proxy for overall body size, decreased significantly in juveniles between 1953 and 2004 and in adults between 1970 and 2004. Skull height and width also decreased significantly in juveniles and adults. This outcome adds to the very mixed picture of the change in body size in mammals under global climate change. The analysis of 50 species of rodents from seven families revealed no significant temporal change in body size (represented mainly by skull dimensions) in 29 species, a significant decline in 13, and an increase in size in eight species (Nengovhela et al. 2020). Of the three carnivore species in which skull size was measured in the second half of the 20th century and analysed in the context of climate change, skull size showed a significant increase in two species and a significant decline in the other (Yom-Tov et al. 2008, 2010a, 2010b). Thus, S. araneus in Białowieża adds to the number of rather rare cases of decreased body sizes among mammals.

The decrease in body size in $S$. araneus in Białowieża is in contrast with the observed increased body size (body and foot length) inSorex cinereus in Alaska during the second half of the twentieth century along with increasing temperature. In $S$. cinereus, the increase was presumably due to higher food availability in winter as a result of improved weather conditions for its prey (Yom-Tov and Yom-Tov 2005). We argue that the smaller size of $S$. araneus in summer could be an effect of increasing drought leading to reduced food availability. The negative impact of decreased soil moisture on the abundance of epigeic and endogeic 
invertebrates has been well documented (Coyle et al. 2017; Singh et al. 2019). S. araneus strongly depend on the abundance of food because their metabolic rates measured under natural conditions equals $258 \%$ of the value predicted for an average mammal of the same body mass (Ochocińska and Taylor 2005). Drought leading to soil moisture deficits may specifically impact earthworms, the main food source of $S$. araneus . $S$. araneusprefer humid habitats with humus-rich soil, as in our study plot, which harbour large numbers of earthworms (Shchipanov et al. 2019).

In support of this, the decrease in skull length in adults between 1970 and 2004 was significantly correlated with the increase in soil moisture deficit, which started to increase in the Białowieża Forest in the 1970s and accelerated in the 1980s (Figures 4e and S2e) as a result of decreasing precipitation (Figures 4d and S2d) and increasing temperatures (Figures 4C, S2a, S2b). The decrease in skull height in both juveniles and adults was correlated with an increase in the mean lifetime temperature (Table 2) and was stronger after 1970, which coincided with the inflection point in precipitation and soil moisture deficit.

There were no regular measurements of the soil water level in the Białowieża Forest before 1985, and those that existed were not comparable with later measurements. However, between 1985 and 2001, the water level decreased in mixed deciduous biotopes by $40 \mathrm{~cm}$. This resulted from an increase in temperature, a decrease in rainfall, and winters without snow and thus a lack of water accumulation at the beginning of the vegetation period (Pierzgalski 2002). The progressive decrease in the soil water level was certainly magnified by the intense drainage work on peatlands in the eastern Belorussian part of the Białowieża Forest in the late 1950s. The average biomass of earthworms in the upper soil layer in the mixed deciduous areas of the Białowieża Forest was $42.2 \mathrm{~g} \mathrm{~m}^{-2}$ between 1997 and 2000 and depended on soil moisture: it was highest in spring, decreased to $22 \%$ of the spring values in summer, and increased to $41 \%$ in autumn (Kowalczyk et al. 2003). This pattern followed the annual course of soil humidity in the Białowieża mixed deciduous forest (Pierzgalski 2002). Earthworms were not available in the forest in winter (Kowalczyk et al. 2003).

While the increasing lifetime temperature affected both juveniles and adults, resulting in lower skull heights, the adults were additionally affected by the conditions in the preceding winter. Milder minimum temperatures in February and decreasing number of days with snow cover in the coldest months of January and February resulted in adults with lower skull heights (Table 2). The lack of snow cover leads to freezing of the upper soil layer and substantially reduces the abundance of various arthropods, which are important components of the winter diet inS. araneus (Templer et al. 2012). Snow generates a relatively mild and stable subnivean microclimate in the litter layer where the shrews live (Coulianos and Johnels 1962; Churchfield et al. 2012) that is not only favourable for their prey but may also diminish the costs of thermoregulation and consequently the food requirements of the shrews (Aitchison 1987). However, the importance of the insulative value of snow for adult $S$. araneus is less convincing, as concluded by the weak relationship between skull height and the number of days with snow cover at least $5 \mathrm{~cm}$ thick in January and February (Table 2).

Skull dimensions in juvenile $S$. araneus from the northeastern part of European Russia were correlated with temperature and precipitation from 1976 to 2003, but in contrast to our results, there was no clear directional trend to the change (Poroshin et al. 2010). This might have been caused by the lack of clear change in weather parameters and/or the shorter time period covered in that study than in ours.

Recent evidence suggests a relationship between the tendency of body size to decline over time and metabolic rates in small mammals. In rodents that do not use torpor, there is a significant negative correlation between the temporal body mass change and basal metabolic rate (BMR; Villar and Naya 2018). Species with a high BMR have become smaller in the last six decades. The size decrease in $S$. araneus, with their lack of ability to hibernate, and the BMR in juvenileS. araneus, which equals $278 \%$ of the value predicted for an average mammal of the same body mass (Ochocińska and Taylor 2005), fits this pattern. It is likely that the relationship between the body size decrease and high metabolic rate is generally true for soricine shrews. Three out of four Sorex species (not including S. cinereus ) had a decreased body mass during the $20^{\text {th }}$ century, and two of them had a significantly decreased body mass (Naya et al. 2017). However, data from different ages and thus Dehnel stages were pooled in this study, potentially affecting the results and hiding the effects of seasonal body size changes. 


\subsection{Changes in the magnitude of Dehnel's phenomenon (1955-1985)}

We found that the decline in skull height from summer to winter inS. araneus from the Białowieża Forest became stronger between 1955 and 1985 (Figures 6a and b). We standardized skull height with skull length in the analysis of Dehnel's phenomenon to describe changes in relative skull height. Relative skull height is strongly correlated with brain size (Bielak and Pucek 1960; Lázaro et al. 2018). Thus, our results also reflected changes in the magnitude of brain size changes. Initially, the skull height of juveniles did not differ between July and August from 1955 to the 1970s (Figure 6b). The skull height in these two months then diverged over the following years (Figure 6b). The smaller skull height in August than in July after 1970 meant that the decrease in skull height started earlier. The magnitude of the decrease was also higher because the relative skull height of winter subadults decreased even more over time (Figure 6).

What is the environmental background of these temporal changes? The increasing magnitude of Dehnel's phenomenon was largely due to the significant decline in the skull height in January and February subadults (Figure 6). Unfortunately, the numbers of available subadult specimens each year were too low to statistically correlate them with weather conditions. The significant decrease in January temperatures until 1972 might explain the increasing magnitude of Dehnel's phenomenon, but January temperatures did not change significantly later on. A seasonal decrease in skull height in $S$. araneus is thought to be anticipatory of harsh winter conditions. The question then arises whether weather conditions in summer and autumn can have direct or indirect impacts on the skull height in winter. Mean daily July temperatures did not change from 1955 to 1985, but August temperatures significantly increased in this period. One may speculate that increasing temperatures and possibly drought could decrease the availability of earthwormsand other invertebrates in August and speed up the decrease in skull height over time (as discussed above), leading to a decrease in skull height in winter. Lower amount of invertebrate food in summer could lead to a greater reduction of resources in winter. Although we did not find a significant change in the soil moisture deficit in August between 1955 and 1985, the sharper skull height decrease with the increasing mean temperature in the driest quarter of the year in a geographic comparison of $S$. araneus (Lázaro et al. 2021) supported the hypothesis that soil moisture deficit might be an important factor for this species. To elucidate this, the role of summer and winter availability of food in Dehnel's phenomenon should be tested under controlled laboratory conditions.

We also found a significantly greater skull height regrowth from 1955 to 1985, which resulted from a steep decrease in skull height in the subadults, while adults did not change (Figure 6). Almost nothing is known about the drivers of this regrowth, which are presumably different from those of the decrease and are likely associated with preparation for the terminal reproductive period in shrews (Lázaro et al. 2019, 2021). Comparison of the skull height regrowth in different $S$. araneus populations revealed only one correlation with weather parameters, namely, a positive correlation with precipitation during the warmest quarter of the year (Lazaro et al. 2021). This also points at changes in food availability.

In summary, we documented a decrease in overall size as represented by absolute skull height and length in the 52-year (1953-2004) skull series and identified increasing temperature and drought as the main correlates of the decrease. Interpreting the results regarding Dehnel's phenomenon, which increased in magnitude because of a sharp size decrease in winter subadults, was more difficult. Our dataset about winter subadults stopped shortly before the time point when climate change became significant, and it would have been interesting to see how subadult size developed after this. There are strong indications that there are important effects of climate on food availability that indirectly cause trends in both skull size and the magnitude of Dehnel's phenomenon. However, this must be clarified experimentally.

With continued climate change, all the parameters that we found to be of importance for the size of the common shrew and its unique winter adaptation are expected to increase even more strongly. The shrew's distribution ranges may be affected by this, as many regions may become too hot and/or dry for these and other cold-adapted animals.

\section{Acknowledgements}


We thank professor Eugeniusz Żukowski for his help with the FORTRAN WATBUG program, and Ewelina Hapunik, MSc, for help in browsing the zoological collection at the Institute of Mammal Biology in Białowieża. Lara Keicher, Jenna Kohles and Ewa Komar commented on the previous version of the manuscript. We did not receive any grants to conduct this research.

\section{Conflict of interest}

The authors declare that they have no conflict of interest.

\section{Author contributions}

Jan R.E. Taylor : Conceptualization (lead); formal analysis (lead); investigation (lead); project administration (supporting), supervision (supporting); visualization (lead); writing - original draft (lead). Marion Muturi : Data curation (lead); writing - original draft (supporting). Javier Lázaro : Conceptualization (equal); methodology (equal), visualization (supporting). Karol Zub : Conceptualization (equal); resources (supporting); writing - original draft (supporting). Dina K.N. Dechmann : Conceptualization (lead); methodology (equal); project administration (lead); supervision (lead); visualization (supporting); writing original draft (considerably supporting).

\section{Ethics approval}

Not applicable - no living animals have been used in this study.

\section{Data availability statement}

Supporting information (Tables S1-S3 and Figures S1-S3 ) and

The primary data on skull sizes and climate change in Białowieża can be found in Dryad: https://doi.org/xxxxxxxx.

\section{References}

Aiello, L.C., \& Wheeler, P. (1995). The Expensive-Tissue Hypothesis.Current Anthropology , 36, 199221.https://doi.org/10.1086/204350

Aitchison, C.W. (1987). Winter energy requirements of soricine shrews.Mammal Review , 17, 2538.https://doi.org/10.1111/j.1365-2907.1987.tb00046.x

Ashton, K.G. (2002). Patterns of within-species body size variation of birds: strong evidence for Bergmann's rule. Global Ecology 83 Biogeography , 11, 505-523.https://doi.org/10.1046/j.1466-822X.2002.00313.x

Ashton, K.G., Tracy, M.C., \& De Queiroz, A. (2000). Is Bergmann's rule valid for mammals? American Naturalist , 156, 390-415.https://doi.org/10.1086/303400

Bielak, T., \& Pucek, Z. (1960). Seasonal changes in the brain weight of the common shrew (Sorex araneus araneus Linnaeus, 1758).Acta Theriologica, 3, 297-300.

Boutin, S., \& Lane, J.E. (2014). Climate change and mammals: evolutionary versus plastic responses. Evolutionary Applications , 7, 29-41.https://doi.org/10.1111/eva.12121

Canale, C.I., Ozgul, A., Allaine, D., \& Cohas, A. (2016). Differential plasticity of size and mass to environmental change in a hibernating mammal. Global Change Biology , 22, 32863303.https://doi.org/10.1111/gcb.13286

Churchfield, S., Rychlik, L., \& Taylor J.R.E. (2012). Food resources and foraging habits of the common shrew, Sorex araneus : does winter food shortage explain Dehnel's phenomenon? Oikos , 121, 15931601.https://doi.org/10.1111/j.1600-0706.2011.20462.x

Cleveland, W.S. (1979). Robust locally weighted regression and smoothing scatterplots. Journal of the American Statistical Association, 74, 829-836. 
Coulianos, C.C., \& Johnels, A.G. (1962). Note on the subnivean wnvironment of small mammals. Arkiv för Zoologi , 15, 363-370.

Coyle, D.R., Nagendra, U.J., Taylor, M.K., Campbell, J.H., Cunard, C.E., Joslin, A.H., Mundepi, A., Phillips, C.A., \& Callaham, M.A. (2017). Soil fauna responses to natural disturbances, invasive species, and global climate change: Current state of the science and a call to action. Soil Biology \& Biochemistry, 110, 116133.https://doi.org/10.1016/j.soilbio.2017.03.008

Dechmann, D.K.N., La Point, S., Dullin C., Hertel, M., Taylor, J.R.E., Zub, K., \& Wikelski, M. (2017). Profound seasonal shrinking and regrowth of the ossified braincase in phylogenetically distant mammals with similar life histories. Scientific Reports , 7, 42443.https://doi.org/10.1038/srep42443

Dehnel, A. (1949). Studies on the genus Sorex L. Annales Universitatis Mariae Curie-Sktodowska, Sectio C , 4, 18-102.

Gardner, J.L., Peters, A., Kearney, M.R., Joseph, L., \& Heinsohn, R. (2011). Declining body size: a third universal response to warming?Trends in Ecology and Evolution , 26, 285291.https://doi.org/10.1016/j.tree.2011.03.005

Hanski, I. (1994). Population biological consequences of body size inSorex . Carnegie Museum Natural History Special Publication, 18, 15-26.

Hume, I.D., Beiglböck, C., Ruf, T., Frey-Roos, F., Bruns, U., \& Arnold, W. (2002). Seasonal changes in morphology and function of the gastrointestinal tract of free-living alpine marmots (Marmota marmota). Journal of Comparative Physiology B , 172, 197-207.https://doi.org/10.1007/s00360-001-0240-1

Isler, K., \& van Schaik, C.P. (2006). Metabolic costs of brain size evolution. Biology Letters , 2, 557560.https://doi.org/10.1098/rsbl.2006.0538

Keicher, L., O'Mara, M.T., Voigt, C.C., \& Dechmann, D.K.N. (2017). Stable carbon isotopes in breath reveal fast metabolic incorporation rates and seasonally variable but rapid fat turnover in the common shrew (Sorex araneus ). Journal of Experimental Biology ,220, 2834-2841.https://doi.org/10.1242/jeb.159947

Kowalczyk, R., Zalewski, A., Jędrzejewsk,a B., \& Jędrzejewski, W. (2003). Spatial organization and demography of badgers (Meles meles ) in Białowieża Primeval Forest, Poland, and the influence of earthworms on badger densities in Europe. Canadian Journal of Zoology, 81, 74-87.https://doi.org/10.1139/z02-233

Lazáro, J., Dechmann, D.K.N., LaPoint, S., Wikelski, M., \& Hertel, M. (2017). Profound reversible seasonal changes of individual skull size in a mammal. Current Biology , 27, R1089R1107.https://doi.org/10.1016/j.cub.2017.08.055

Lazáro, J., Hertel, M., LaPoint, S., Wikelski, M., Stiehler, M., \& Dechmann, D.K.N. (2018). Cognitive skills of common shrews (Sorex araneus) vary with seasonal changes in skull size and brain mass. Journal of Experimental Biology , 221, jeb166595.https://doi.org/10.1242/jeb.166595

Lazáro, J., Hertel, M., Muturi, M., \& Dechmann, D.K.N. (2019). Seasonal reversible size changes in the braincase and mass of common shrews are flexibly modified by environmental conditions. Scientific Reports , 9, 2489.https://doi.org/10.1038/s41598-019-38884-1

Lazáro, J., Nováková, L., Hertel, M., Taylor, J.R.E., Muturi, M., Zub, K., \& Dechmann, D.K.N. (2021). Geographic patterns in seasonal changes of body mass, skull and brain size of common shrews. Ecology and Evolution , 11, 2431-2448.https://doi.org/10.1002/ece3.7238

McNab, B.K. (1991). The energy expenditure of shrews. In J.S. Findley \& T.L. Yates (Eds.), The Biology of the Soricidae (pp. 35-45). The Museum of Southwestern Biology Special Publication 1.

McNab, B.K. (2010). Geographic and temporal correlations of mammalian size reconsidered: a resource rule. Oecologia , 164, 13-23.https://doi.org/10.1007/s00442-010-1621-5 
Mezhzherin, V.A. (1964). Dehnel's phenomenon and its possible explanation. Acta Theriologica, 8, 95-114 (in Russian with English summary).

Naya, D.E., Naya, H., \& Cook, J. (2017). Climate change and body size trends in aquatic and terrestrial endotherms: Does habitat matter? PloS ONE , 12: e0183051.https://doi.org/10.1371/journal.pone.0183051

Nengovhela, A., Denys, C., \& Taylor, P.J. (2020). Life history and habitat do not mediate temporal changes in body size due to climate warming in rodents. PeerJ , 8: e9792.https://doi.org/10.7717/peerj.9792

Ochocińska, D., \& Taylor, J.R.E. (2003). Bergmann's rule in shrews: geographical variation of body size in Palearctic Sorex species.Biological Journal of the Linnean Society , 78, 365381.https://doi.org/10.1046/j.1095-8312.2003.00150.x

Ochocińska, D., \& Taylor, J.R.E. (2005). Living at the physiological limits: field and maximum metabolic rates of the common shrew (Sorex araneus ). Physiological and Biochemical Zoology , 78, 808818.https://doi.org/10.1086/431190

Parmesan, C. (2006). Ecological and evolutionary responses to recent climate change. Annual Review of Ecology, Evolution, and Systematics , 37, 637-669.https://doi.org/10.1146/annurev.ecolsys.37.091305.110100

Piersma, T., Gudmundsson, G., \& Lilliendahl, K. (1999). Rapid changes in the size of different functional organ and muscle groups during refueling in a long-distance migrating shorebird. Physiological and Biochemical Zoology , 72, 405-415.https://doi.org/10.1086/316680

Pierzgalski, E., Boczoń, A., \& Tyszka, J. (2002). Variability of precipitation and ground water level in the Białowieża National Park.Kosmos , 51, 415-425 [in Polish with English summary].

Poroshin, E.A., Polly, P.D., \& Wójcik, J.M. (2010). Climate and morphological change on decadal scales: Multiannual variation in the common shrew Sorex araneus in Northeastern Russia. Acta Theriologica, 55, 193-202.https://doi.org/10.4098/j.at.0001-7051.106.2009

Pucek, Z. (1963). Seasonal changes in the braincase of some representatives of the genus Sorex from the Palearctic.Journal of Mammalogy , 44, 523-536.https://doi.org/10.2307/1377135

Pucek, Z. (1970). Seasonal and age change in shrews as an adaptive process. Symposia of the Zoological Society of London, 26, 189-207.

Pucek, Z. (1981). Order Insectivores - Insectivora. In: Keys to Vertebrates of Poland: Mammals (pp. 62-101). PWN - Polish Scientific Publishers, Warszawa.

R Core Team. (2016). R: a language and environment for statistical computing, version 3.3.1. Vienna, Austria. $\mathrm{R}$ Foundation for Statistical Computing.

Sauer, J.R., \& Slade, N.A. (1987). Size-based demography of vertebrates. Annual Review of Ecology and Systematics , 18, 71-90.https://doi.org/10.1146/annurev.es.18.110187.000443

Schaeffer, P.J., O’Mara, M.T., Breiholz, J., Keicher, L., Lázaro, J., Muturi, M., \& Dechmann, D.K.N. (2020). Metabolic rate in common shrews is unaffected by temperature, leading to lower energetic costs through seasonal size reduction. Royal Society Open Science, 7, 191989.https://doi.org/10.1098/rsos.191989

Shchipanov, N.A., Zima, J., \& Churchfield, S. (2019). Introducing the common shrew. In J.B. Searle, P.D. Polly \& J. Zima (Eds.),Shrews, Chromosomes and Speciation (pp. 19-67). Cambridge University Press, Cambridge.

Singh, J., Schädler, M., Demetrio, W., \& Brown, G.G., Eisenhauer N. (2019). Climate change effects on earthworms - a review. Soil Organisms , 91, 113-137.https://doi.org/10.25674/so91iss3pp114

Taylor, J.R.E. (1998). Evolution of energetic strategies in shrews. In J.M. Wójcik, \& M. Wolsan (Eds.). Evolution of Shrews (pp. 309-346). Mammal Research Institute, Białowieża, Polish Academy od Sciences. 
Taylor, J.R.E, Rychlik, L., \& Churchfield, S. (2013). Winter reduction in body mass in a very small, nonhibernating mammal: Consequences for heat loss and metabolic rates. Physiological and Biochemical Zoology , 86, 9-18.https://doi.org/10.1086/668484

Templer, P.H., Schiller, A.F., Fuller, N.W., Socci, A.M., Campbell, J.L., Drake, J.E., \& Kunz, T.H. (2012). Impact of a reduced winter snowpack on litter arthropod abundance and diversity in a northern hardwood forest ecosystem. Biology and Fertility of Soils , 48, 413-424.https://doi.org/10.1007/s00374-011-0636-3

Teplitsky, C., \& Millien, V. (2014). Climate warming and Bergmann's rule through time: is there any evidence? Evolutionary Applications , 7, 156-168.https://doi.org/10.1111/eva.12129

Villar, C.H., \& Naya, D.E. (2018). Climate change and temporal trends in body size: the case of rodents. Oikos , 127, 1186-1194.https://doi.org/10.1111/oik.04884

Walther, G.R., Post, E., Convey, P., Menzel, A., Parmesan, C., Beebee, T.J.C., Fromentin, J.M., HoeghGuldberg, O., \& Bairlein, F. (2002). Ecological responses to recent climate change. Nature , 416, 389395.https://doi.org/10.1038/416389a

Willmott, C.J. (1977). WATBUG: a FORTRAN IV algorithm for calculating the climatic water budget. $\quad C W$ Thornthwaite Associates Laboratory of Climatology, Publications in Climatology , 30, 155.http://udspace.udel.edu/handle/19716/20487

Yom-Tov, Y., \& Geffen, E. (2011). Recent spatial and temporal changes in body size of terrestrial vertebrates: probable causes and pitfalls.Biological Reviews, 86, 531-541.https://doi.org/10.1111/j.1469185X.2010.00168.x

Yom-Tov, Y., Leader, N., Yom-Tov, S., \& Baagøe, H. J. (2010a). Temperature trends and recent decline in body size of the stone martenMartes foina in Denmark. Mammalian Biology , 75, 146150.https://doi.org/10.1016/j.mambio.2008.10.005

Yom-Tov, Y., Roos, A., Mortensen, P., Wiig, Ø., Yom-Tov, S., \& Heggberget, T. M. (2010b). Recent changes in body size of the Eurasian otter Lutra lutra in Sweden. Ambio , 39, 496-503.https://doi.org/10.1007/s13280$010-0074-8$

Yom-Tov, Y., \& Yom-Tov, J. (2005). Global warming, Bergmann's rule and body size in the masked shrew Sorex cinereus Kerr in Alaska.Journal of Animal Ecology , 74, 803-808.https://doi.org/10.1111/j.13652656.2005.00976.x

Yom-Tov, Y., Yom-Tov, S., \& Jarrell, G. (2008). Recent increase in body size of the American marten Martes americana in Alaska.Biological Journal of the Linnean Society, 93, 701-707.https://doi.org/10.1111/j.10958312.2007.00950.x

TABLE 1 The significance of the regression slopes of the relationships between skull dimensions and time (year) in juvenile and adult $S$. araneus from 1953 to 2004. All significant relationships were negative and marked in bold

\begin{tabular}{lllll}
\hline & Juveniles $\mathrm{n}=234$ & Juveniles $\mathrm{n}=234$ & Adults $\mathrm{n}=114$ & Adults $\mathrm{n}=114$ \\
\hline Skull height & $F_{1,232}=8.85$ & $P=\mathbf{0 . 0 0 3 2}$ & $F_{1,112}=7.70$ & $P=\mathbf{0 . 0 0 6 5}$ \\
Skull width & $F_{1,232}=8.48$ & $P=\mathbf{0 . 0 0 4 0}$ & $F_{1,112}=8.09$ & $P=\mathbf{0 . 0 0 5 3}$ \\
Skull length & $F_{1,232}=12.24$ & $P=\mathbf{0 . 0 0 0 6}$ & $F_{1,112}=3.03$ & $P=0.085$ \\
\hline
\end{tabular}

TABLE 2 The relationship of the change in skull height in juvenile (July) and adult $S$. araneus with weather variables between 1953 and 2004. All regressions, except mean daily temperature for juveniles, were corrected for autocorrelation (see Methods). $r^{2}$ is the proportion of the data explained by each weather variable; significant $P$ values are shown in bold. The direction of significant relationships is shown in parentheses. There were fewer than 52 analysed years because we did not have skull measurements from all 


\begin{tabular}{|c|c|c|}
\hline Age and weather variables & $r^{2}$ & $P$ \\
\hline \multicolumn{3}{|l|}{ Juveniles ( $\mathrm{n}=45$ years $)$} \\
\hline \multicolumn{3}{|l|}{ Whole-life weather ${ }^{\mathrm{a}}$} \\
\hline Mean daily temperature & $0.117(-)$ & 0.021 \\
\hline Sum of precipitation & $<0.001$ & 0.99 \\
\hline Sum of soil moisture deficit & 0.051 & 0.14 \\
\hline \multicolumn{3}{|l|}{ Adults $(\mathrm{n}=32$ years $)$} \\
\hline \multicolumn{3}{|l|}{ Whole-life weather ${ }^{\mathrm{b}}$} \\
\hline Mean daily temperature & $0.157(-)$ & 0.027 \\
\hline Sum of precipitation & 0.003 & 0.79 \\
\hline Sum of soil moisture deficit & $<0.001$ & 0.98 \\
\hline \multicolumn{3}{|l|}{ Impact of previous winter } \\
\hline $\begin{array}{l}\text { Mean temperature of January and } \\
\text { February }\end{array}$ & 0.054 & 0.21 \\
\hline $\begin{array}{l}\text { Lowest average daily temperature } \\
\text { of }\end{array}$ & 0.038 & 0.30 \\
\hline \multicolumn{3}{|l|}{ January } \\
\hline $\begin{array}{l}\text { Lowest average daily temperature } \\
\text { of }\end{array}$ & $0.126(-)$ & 0.0499 \\
\hline \multicolumn{3}{|l|}{ February } \\
\hline Number of days with snow cover & 0.039 & 0.289 \\
\hline $\begin{array}{l}\text { Number of days with snow cover } \\
\text { in January and February }\end{array}$ & $0.216(+)$ & 0.0084 \\
\hline $\begin{array}{l}\text { Number of days with snow cover } \\
>=5 \mathrm{~cm} \text { in January and February }\end{array}$ & $0.113(+)$ & 0.065 \\
\hline
\end{tabular}

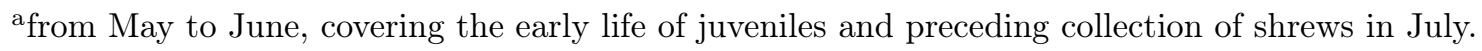

${ }^{b}$ from June, when the first cohort of shrews was weaned, to March of the following year when shrews were collected between April and August

TABLE 3 a Results of the ANCOVA testing the relationship between skull height, width and length and age category (juveniles from July, subadults and adults) and year of sampling in $S$. araneus in Białowieża from 1955 to 1985. Significant effects are marked bold. b Mean dimensions of skull (in $\mathrm{cm}$ ) with standard errors, reported for three age categories; different letters (a, b, c) mark significant differences between age categories (at $P=0.05)$

\begin{tabular}{lllll}
\hline (a) & Skull & Skull & Skull & Skull \\
\hline Age & $\mathrm{n}$ & Height & Width & Length \\
& 295 & $F_{2,291}=390.8$ & $F_{2,291}=10.3$ & $\begin{array}{l}F_{2,291}=38.3 \\
\text { Year }\end{array}$ \\
& & $P<\mathbf{0 . 0 0 0 1}$ & $P<\mathbf{0 . 0 0 0 1}$ & $\begin{array}{l}P<\mathbf{0 . 0 0 0 1} \\
F_{1,291}=2.84\end{array}$ \\
(b) & & $F_{1,291}=6.4$ & $F_{1,291}=0.49$ & $P=0.093$ \\
$\begin{array}{l}\text { Juveniles } \\
\text { (July) }\end{array}$ & & $P=\mathbf{0 . 0 1 2}$ & $P=0.48$ & \\
$\begin{array}{l}\text { Subadults } \\
\text { Adults }\end{array}$ & 151 & $0.618 \pm 0.002^{\mathrm{a}}$ & $1.020 \pm 0.002^{\mathrm{a}}$ & $1.996 \pm 0.003^{\mathrm{a}}$ \\
\hline
\end{tabular}


TABLE 4 Dehnel's phenomenon in $S$. araneus : the change in skull height, corrected with skull length, from summer juveniles to winter subadults and from winter subadults to next-summer adults from 1955 to 1985

\begin{tabular}{llll}
\hline & Change in skull height & Change in skull height & Change in skull height \\
\hline & Juveniles (July) to & Juveniles (August) to & Subadults to adults \\
subadults $\mathrm{n}=221$ & subadults $\mathrm{n}=122$ & $\mathrm{n}=144$ \\
Year & $F_{1,216}=14.8 P=\mathbf{0 . 0 0 0 2}$ & $F_{1,117}=31.3 P<\mathbf{0 . 0 0 0 1}$ & $F_{1,139}=10.8 P=\mathbf{0 . 0 0 1 3}$ \\
Age & $F_{1,216}=10.9 P=\mathbf{0 . 0 0 1 1}$ & $F_{1,117}=0.83^{\mathrm{a}} P=0.364$ & $F_{1,139}=10.1 P=\mathbf{0 . 0 0 1 9}$ \\
Skull length & $F_{1,216}=28.8 P<\mathbf{0 . 0 0 0 1}$ & $F_{1,117}=7.09 P=\mathbf{0 . 0 0 8 9}$ & $F_{1,139}=20.7 P<\mathbf{0 . 0 0 0 1}$ \\
Year $\times$ age & $F_{1,216}=11.7 P=0.0008$ & $F_{1,117}=0.72 P=0.398$ & $F_{1,139}=10.4 P=\mathbf{0 . 0 0 1 6}$ \\
\hline
\end{tabular}

${ }^{a}$ After removal of the nonsignificant interaction, the significance of age was $F_{1,118}=230.4, P<0.0001$; the significance of year and skull length remained very similar $\left(F_{1,118}=31.2, P<0.0001 ; F_{1,118}=7.04, P=0.0090\right.$, respectively).

Figure legends

FIGURE 1 The common shrew (Sorex araneus). Photo by Leszek Rychlik.

FIGURE 2 X-ray images of $S$. araneus skulls and linear measurements taken from the images: a skull length (SKL), skull (braincase) height (BCH), and b skull width (BCW). See text for details

FIGURE 3 Skull height throughout the lifetime of $S$. araneus. Sampling months and corresponding age categories are shown. The first weaned shrews appeared in June (juveniles), which is when skull dimensions were largest; they then shrank towards winter (subadults) and finally regrew in the next spring/summer (adults), when the adults reproduced. Most of the shrews then died before the next winter. Solid circles are the means \pm standard error when the sample size was [?]5. Horizontal bars represent age categories and months from which skulls were analyzed; skulls of juvenile shrews from July and August were analyzed separately (see text). The presented data were limited to the period between 1955 and 1985, for which we had individuals from all three age categories

FIGURE 4 The relationships between a skull height,b skull length and year in July juveniles (JUV-7; 19532004), August juveniles (JUV-8; 1953-1981), subadults (SAD; 1955-1985) and adults (AD; 1953-2004) of $S$. araneus, compared with changing climate parameters: c the mean annual temperature, dthe annual sum of precipitation, and e the annual sum od soil moisture deficit. The $95 \%$ confidence limits of the relationships smoothed with LOESS are shown (for the sake of clarity, confidence limits for JUV-8 and SAD in $\mathbf{b}$ are not presented)

FIGURE 5 Relationship between the skull length in adult $S$. araneus and the annual soil moisture deficit. Each circle represents one year (between 1971 and 2004), and the size of the circle is proportional to the number of skulls measured (one to seven); the period for which the soil moisture deficit was calculated is explained in Table 2

FIGURE 6 Dehnel's phenomenon in S. araneus from 1953 to 1985; a comparison of skull height in three consecutive time intervals (see Figure 3 for information on the shrews' life history). Solid lines and shaded areas represent fitted values and standard errors of the GAM model ( $\mathrm{n}=392, P<0.001$ for the three time intervals, deviance explained 69.7\%); b differences in skull height between July juveniles (JUV-7), August juveniles (JUV-8), winter subadults (SAD) and adults (AD) across years (comparison of regression lines). Arrows indicate the sequence of age classes and seasonal changes in $S$. araneus 

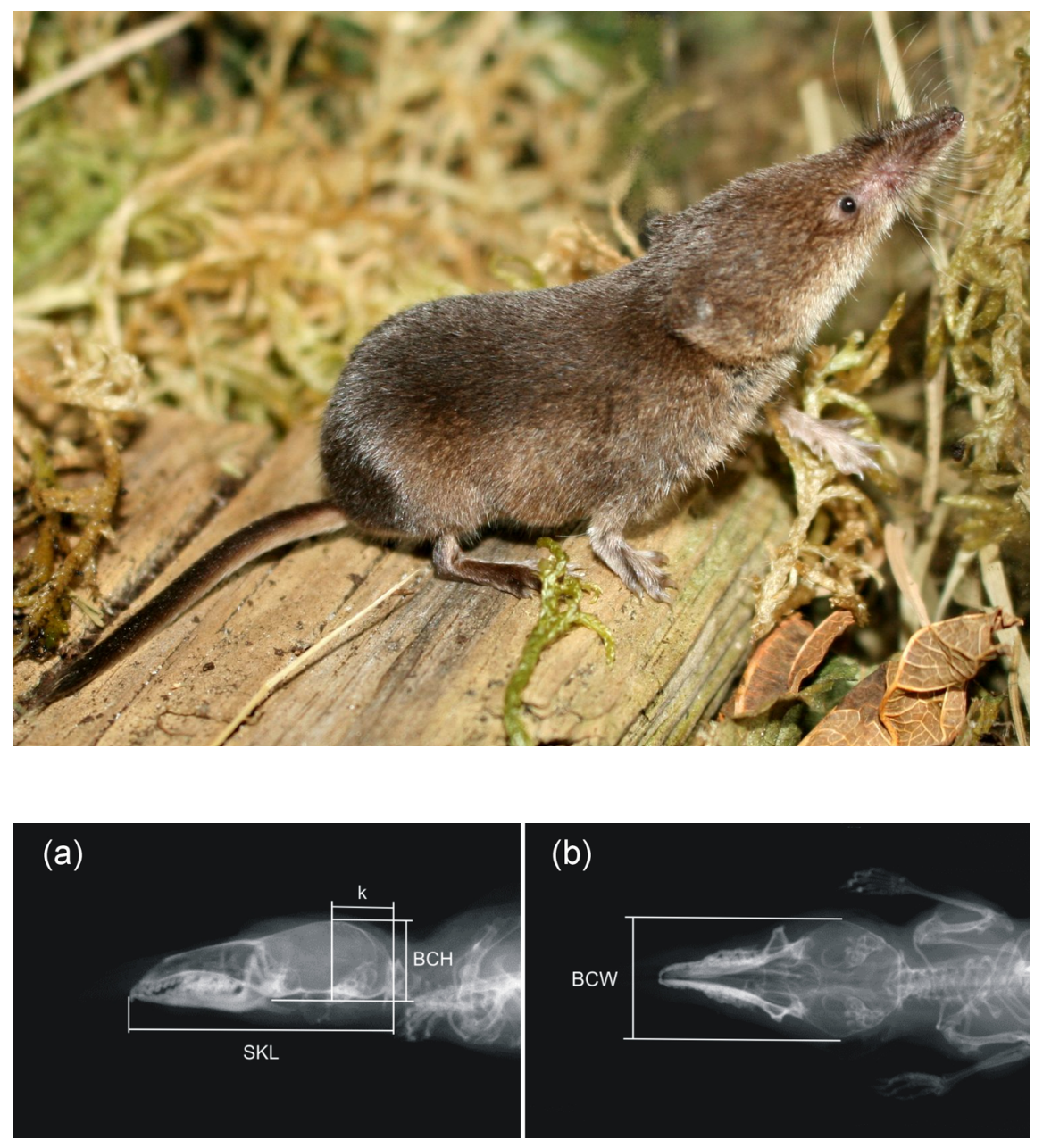


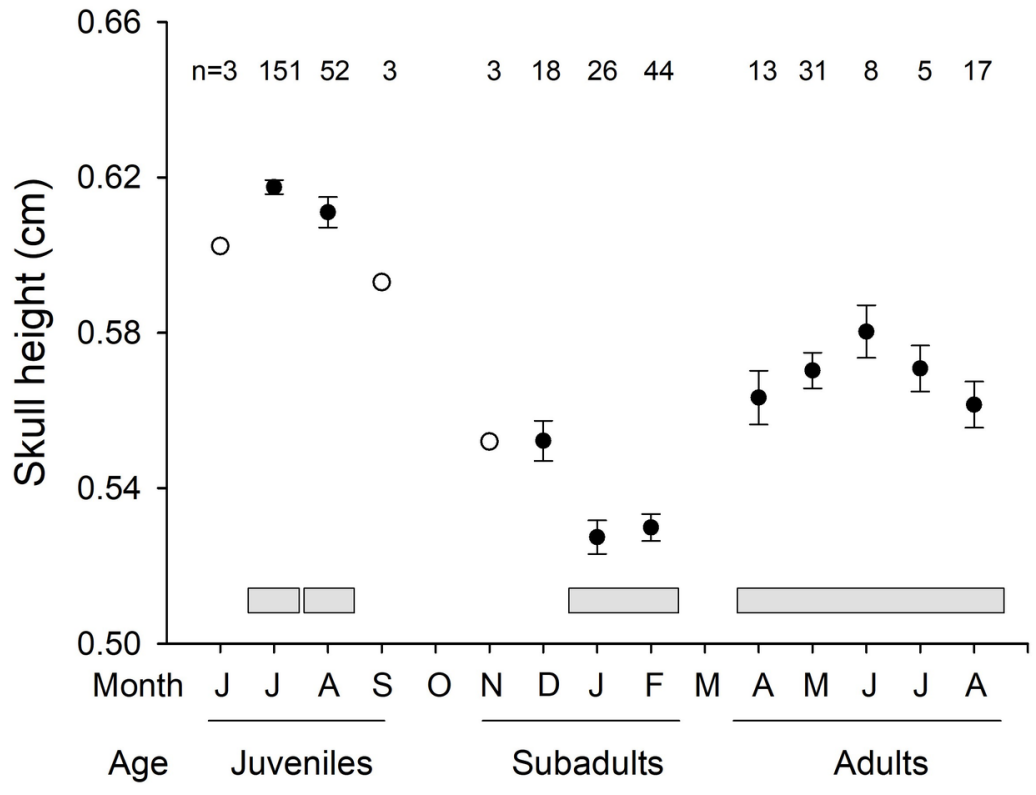



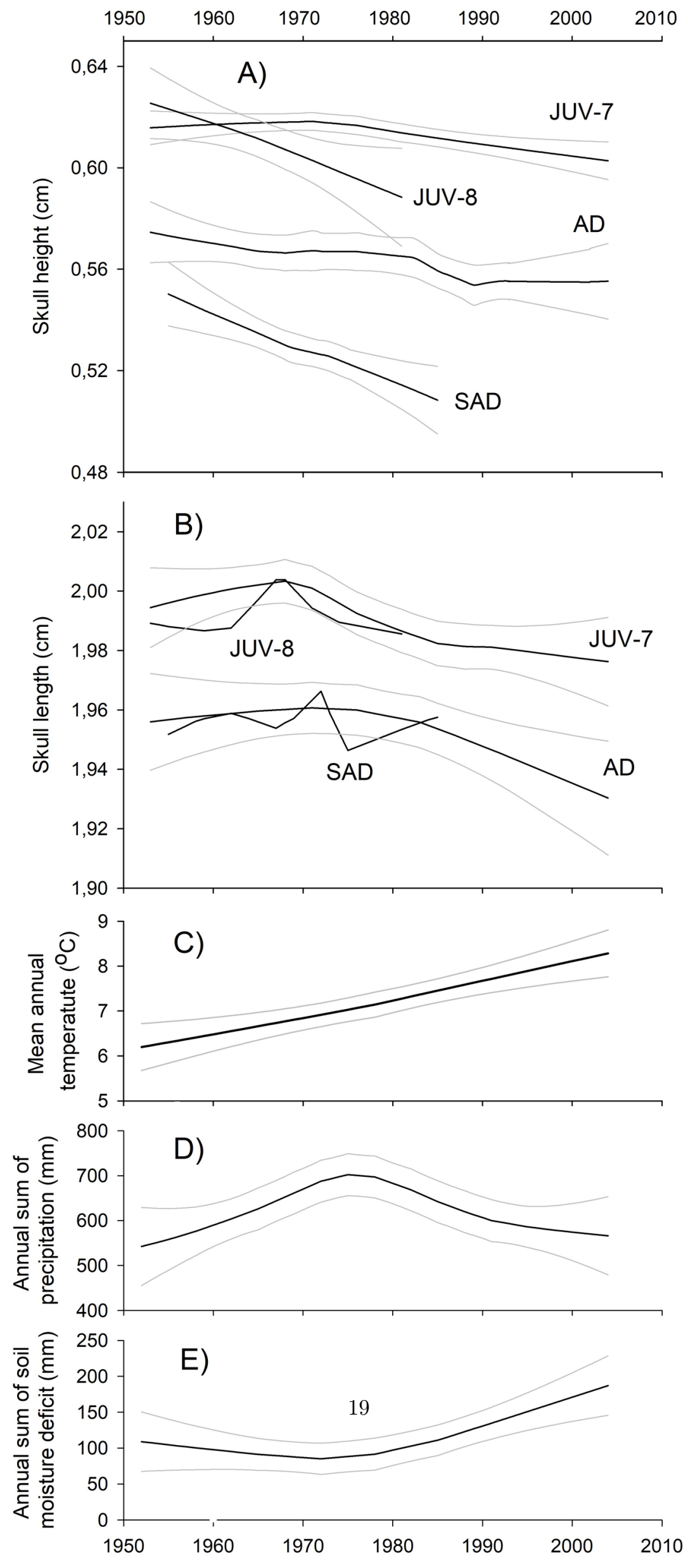


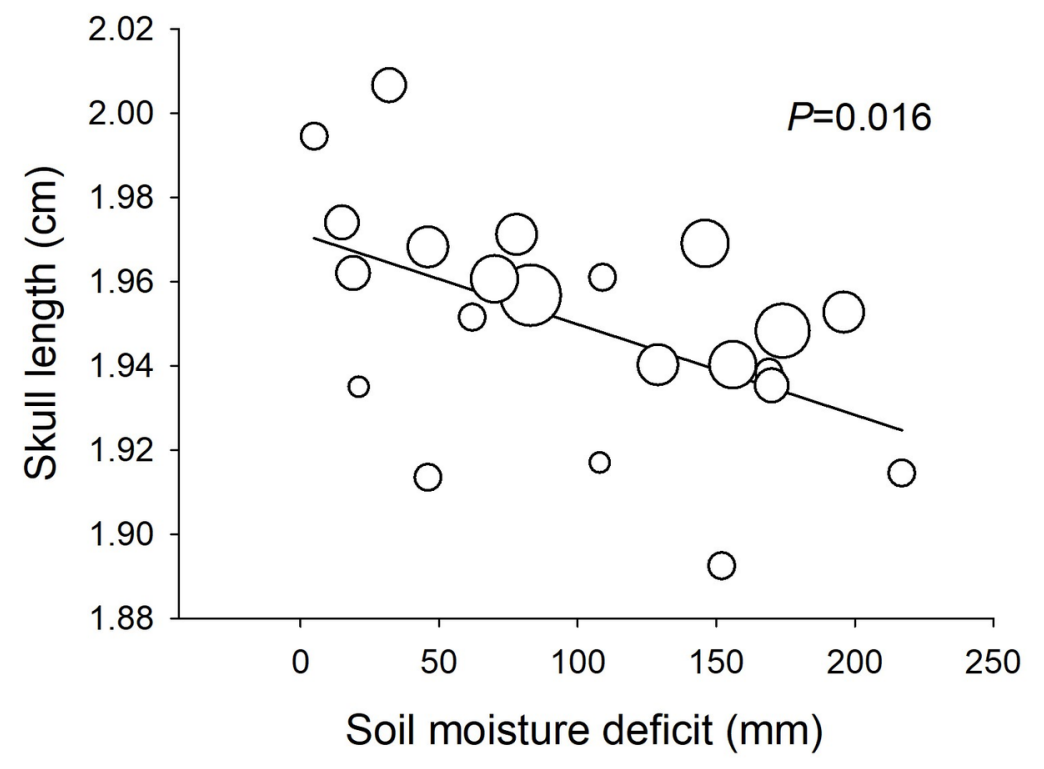




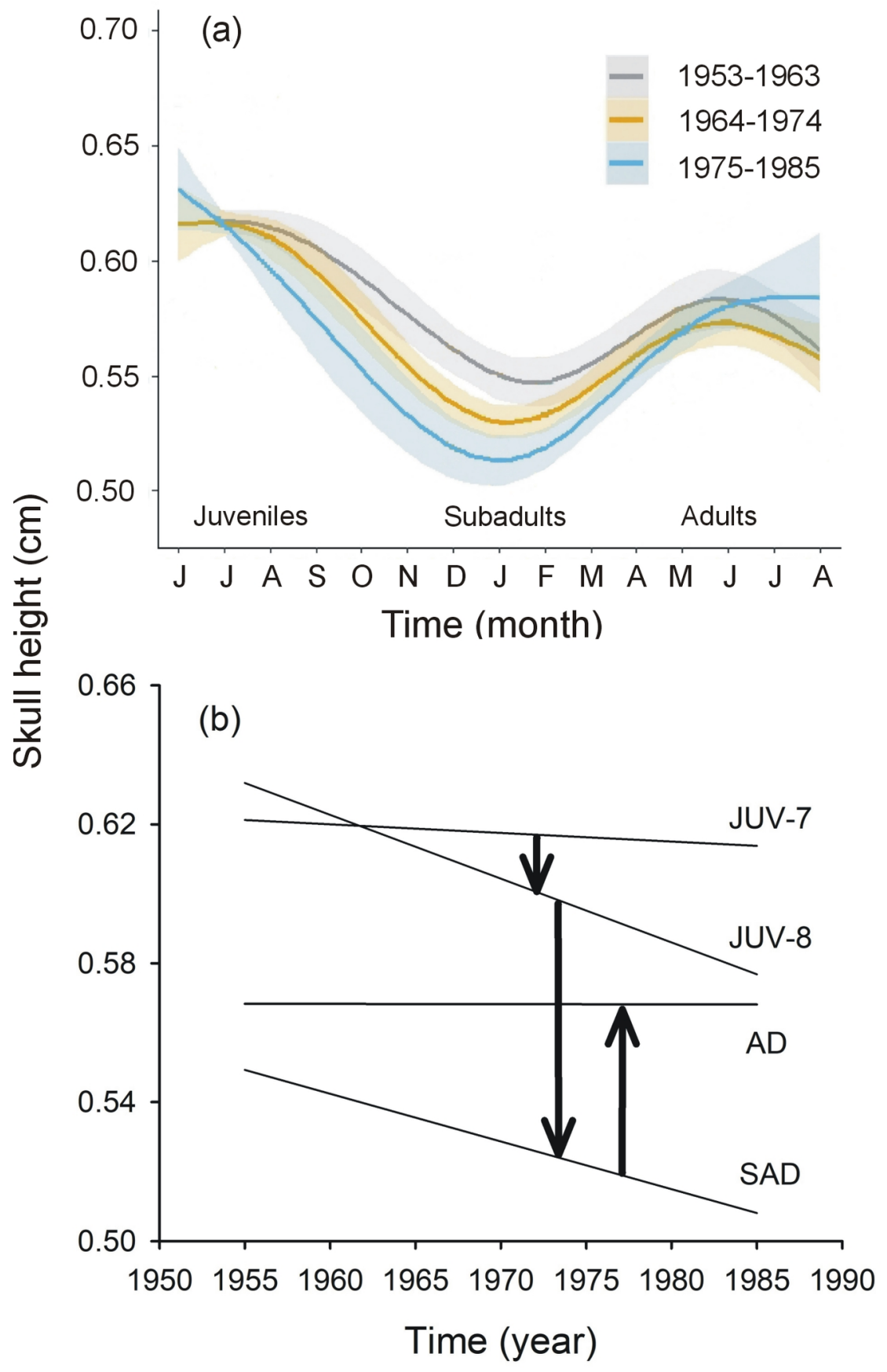

